\title{
Pediatric Ophthalmology Fellowship Survey: Fellows Selection Criteria for Training Programs
}

\author{
Jasleen K. Singh, MD $\quad$ Kimberly Lovelace, $\mathrm{MD}^{2} \quad$ Jennifer L. Patnaik, $\mathrm{PhD}^{1} \quad$ Robert Enzenauer, MD \\ ${ }^{1}$ Department of Ophthalmology, University of Colorado-Denver, \\ Aurora, Colorado \\ 2 Monroe Clinic, Monroe, Wisconsin \\ Address for correspondence Jasleen K. Singh, MD, Department of \\ Ophthalmology, University of Colorado-Denver, 13123 E 16th ave \\ B430, Aurora, CO 80045 (e-mail: jasleen.singh@ucdenver.edu).
}

J Acad Ophthalmol 2018;10:e140-e142.

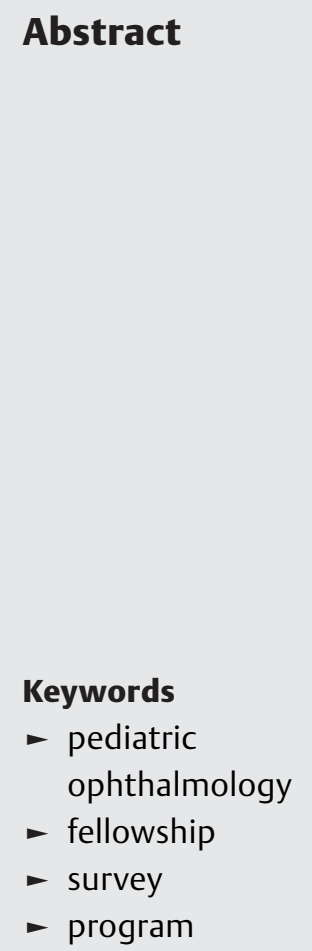

Purpose This article investigates the characteristics that trainees look for in a pediatric ophthalmology fellowship program.

Methods A 14-question anonymous survey was created and sent out via the United States Postal Service to all physicians of American Association of Pediatric Ophthalmology and Strabismus. The survey addressed demographics, the interview process, and the qualities of fellowship training programs that were important factors in ranking fellowship training programs. A Likert scale was used to rate different qualities (1: not important, 9: very important) and summary statistics were reported as overall means and standard deviations.

Results In total, 1,061 were mailed out with 413 returned amounting to a $38.9 \%$ response rate. The qualities with the highest mean were diversity of surgical procedures, volume of procedures/surgeries, reputation of the fellowship director, advice from mentor, emphasis on type of surgery performed, program association with an academic institution, and national reputation of program. The characteristics that ranked the lowest were presence of a Veteran's Administration hospital and presence of a county hospital. Females rated proximity to family significantly higher than males. Among responders who ranked volume of procedures/surgeries as very important, strabismus surgery was the most important.

Conclusion Pediatric ophthalmologists chose fellowship training programs based on the diversity and surgical volume of procedures and the reputation of the program director.
Residents in ophthalmology have a desire to pursue fellowship after their initial training. About $64 \%$ of residents decide to pursue a fellowship, and of those approximately $10 \%$ choose pediatric ophthalmology. ${ }^{1}$ Factors influencing residents to pursue a fellowship include obtaining new skills and becoming more marketable for jobs. The top reasons for residents to not pursue a subspecialty in pediatric ophthalmology include a low interest in the clinical field despite good training in residency, aversion to working with children, and lower financial compensation. Pediatric ophthalmologists do have high job satisfaction in areas ranging from diversity of pathology, intellectually stimulating field, and good lifestyle. ${ }^{2}$

received

February 22, 2018 accepted after revision July 27,2018
DOI https://doi.org/ 10.1055/s-0038-1669930. ISSN 2475-4757.
Pediatric ophthalmology fellowship is one of the many fellowships offered in ophthalmology. It includes a 1-year fellowship in pediatric ophthalmology and strabismus, which can include adult strabismus. The fellowship match is through the San Francisco Matching Program (SF Match). According to the SF Match statistics, the number of positions offered in pediatric ophthalmology has remained stable at 57 to 62 spots per year. However, pediatric ophthalmology has remained the subspecialty with the most vacancies per year. ${ }^{3}$

Given the fewer number of applicants pursuing pediatric ophthalmology than the number of positions available, fellowship programs are in competition for the best candidates.
Copyright $\odot 2018$ by Thieme Medical Publishers, Inc., 333 Seventh Avenue, New York, NY 10001, USA. Tel: +1(212) 584-4662.
License terms

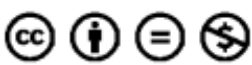


However, each program has its own criteria for what they consider an ideal fellow. There is a desire to learn more about what characteristics applicants consider in choosing a fellowship program. This article highlights these characteristics to help fellowship program directors to better understand what aspects of fellowship are most valued.

\section{Methods}

A 14-question anonymous survey was created and included questions about applicants' demographic data, the application and interview process in pediatric ophthalmology, and the qualities of a fellowship program that were important to the applicant. This survey was modeled after a similar survey given to the members of the American Society of Ophthalmic and Plastic and Reconstructive Surgery in regard to their fellowship match. ${ }^{4}$ This is available in -Supplementary Material (online only). The qualities of the fellowship were ranked on a 9-point Likert scale (1: not important and 9: very important).

Prior pediatric ophthalmology fellows were identified using the American Association of Pediatric Ophthalmology and Strabismus (AAPOS) physician member database. The survey was then mailed to AAPOS members via addresses identified in the member database. Respondents were asked to mail the completed survey back for statistical analysis.

The demographics of the respondent pool were analyzed with simple statistics. The fellowship program qualities were evaluated with means and standard deviations. The provided results are given as means and standard deviations for the entire respondent population. Comparisons were done between demographic groups (gender, practice environment, and years of training) using Benjamin-Hochberg adjustment for multiple testing. Comparisons with a $p$-value of $<0.05$ after the adjustment were considered significant.

\section{Results}

A total of 1,061 surveys were mailed, with 413 received, a $38.9 \%$ response rate. Of the respondents, $58.4 \%$ were male, and $41.6 \%$ were female. Additional demographic data are reported in - Table 1.

Most respondents applied either to 1,5 , or more than 10 to 19 AAPOS programs. Similarly, most respondents received interviews to 1,5 , or more than 10 to 19 programs. Most respondents attended five or less interviews.

The program qualities (summarized in - Table 2) that had the highest mean response was diversity of surgical procedures and volume of procedures/surgeries performed. This was followed by reputation of the fellowship director, advice from mentor, and national reputation of the program. Emphasis on the type of surgery performed was ranked at a mean of 7.5 with a standard deviation of 1.6. Those who ranked emphasis on the type of surgeries performed with a rating between 6 and 9 on a Likert scale were asked to rank the type of surgery that was the most important. Respondents ranked strabismus surgery as the most important followed by cataract surgery, oculoplastics,
Table 1 Demographic data of respondents, $N=413$

\begin{tabular}{|l|l|l|}
\hline & $n$ & $\%$ \\
\hline Gender & & \\
\hline Male & 241 & 58.4 \\
\hline Female & 172 & 41.6 \\
\hline Spouse & & \\
\hline Yes & 332 & 80.6 \\
\hline No & 80 & 19.4 \\
\hline Children & & \\
\hline Yes & 253 & 61.4 \\
\hline No & 159 & 38.6 \\
\hline Years of training & & \\
\hline Prior to 1989 & 129 & 31.2 \\
\hline $1989-1998$ & 118 & 28.6 \\
\hline $1999-2008$ & 92 & 22.3 \\
\hline $2009-2012$ & 74 & 17.9 \\
\hline Practice environment in 5 y & & \\
\hline Private practice & 166 & 40.6 \\
\hline Academic practice & 114 & 27.9 \\
\hline Private and academic practice & 128 & 31.3 \\
\hline Military & 1 & 0.2 \\
\hline
\end{tabular}

retinopathy of prematurity treatment, and glaucoma in descending order.

The program qualities that were ranked the lowest based on all respondents were the presence of a Veteran's Administration hospital, presence of a county hospital, benefits, proximity to family, and research opportunities.

When comparing these program qualities' Likert item ratings between the genders of the applicant, the mean rating of proximity to family was higher for females compared with males. There was a statistical difference in valuing research reputation of program and research opportunities when comparing those whose future practice environment was an academic institution or private practice with academic affiliation than those whose practice environment was private practice alone. Benefits, number of preceptors, and fellow call responsibility were rated significantly higher in more recent applicants (20092012) than applicants before 1989 and reputation of fellowship director was rated significantly lower in these recent applicants.

The last question of the survey asked the respondents to write what they considered the most important quality that influenced their fellowship program ranking and selection. There were a variety of responses including "mentor advice," "fellowship director," and "autonomy/independence of fellow and surgery." The most common responses among all respondents were "program reputation," "variety and volume of procedures," "location," "environment of the department," and "fellowship director." 
Table 2 Mean Likert rating of program characteristics (from highest to lowest rating)

\begin{tabular}{|l|l|l|}
\hline Quality & $\boldsymbol{n}$ & Mean (SD) \\
\hline Diversity of surgical procedures & 409 & $8.0(1.4)$ \\
\hline Volume of procedures/surgeries & 409 & $8.0(1.5)$ \\
\hline Reputation of fellowship director & 411 & $7.7(1.8)$ \\
\hline Advice from mentor & 409 & $7.6(1.7)$ \\
\hline National reputation of program & 410 & $7.5(1.8)$ \\
\hline $\begin{array}{l}\text { Emphasis on type of } \\
\text { surgery performed }\end{array}$ & 408 & $7.5(1.6)$ \\
\hline $\begin{array}{l}\text { Program associated with } \\
\text { academic institution }\end{array}$ & 410 & $7.5(1.8)$ \\
\hline Patient diversity & 413 & $6.8(2.1)$ \\
\hline Presence of children's hospital & 412 & $6.6(2.5)$ \\
\hline Interview & 396 & $6.5(2.1)$ \\
\hline $\begin{array}{l}\text { Reputation of larger cognate } \\
\text { ophthalmology department }\end{array}$ & 408 & $6.5(2.1)$ \\
\hline Didactics & 412 & $6.5(1.9)$ \\
\hline Collaboration with other specialties & 410 & $6.5(1.9)$ \\
\hline Number of preceptors & 413 & $6.4(2.0)$ \\
\hline Appointments of fellowship graduates & 406 & $6.1(2.2)$ \\
\hline Fellow clinic & 405 & $6.0(2.1)$ \\
\hline Spousal considerations & 383 & $5.8(2.9)$ \\
\hline Appeal of city & 409 & $5.7(2.4)$ \\
\hline Teaching responsibilities & 411 & $5.5(2.0)$ \\
\hline Research reputation of program & 409 & $5.3(2.2)$ \\
\hline Fellow call responsibility & 411 & $5.1(2.2)$ \\
\hline Research opportunities & 413 & $4.9(2.1)$ \\
\hline Proximity to family & 411 & $4.7(3.0)$ \\
\hline Benefits & 413 & $4.6(2.2)$ \\
\hline Presence of county hospital & 408 & $3.3(2.4)$ \\
\hline $\begin{array}{l}\text { Presence of Veteran's } \\
\text { Administration hospital }\end{array}$ & $2.8(2.1)$ \\
\hline
\end{tabular}

Abbreviation: SD, standard deviation.

\section{Discussion}

Knowing what applicants consider important when choosing a fellowship program is very helpful for fellowship directors. The overall most important aspects of fellowship training were volume and diversity of surgical procedures, mentorship, and reputation of the program and fellowship director. This is very much related to what pediatric ophthalmologists value in their job satisfaction of diversity of pathology and intellectually stimulating. ${ }^{2}$

A similar survey was conducted for evaluating characteristics important in oculoplastics fellowship training. ${ }^{4}$ In this survey, respondents highly valued a variety and volume of surgical cases, personality of program director, the interview, and an emphasis on the type of surgeries performed. Pediatric ophthalmology respondents were similar in considering the surgical aspect of fellowship training as the most important.
Another pediatric-based surgery fellowship surveyed respondents in 2010 on program characteristics that are considered important. ${ }^{5}$ Similar to pediatric ophthalmology, pediatric surgery valued "diversity of cases," "advice from mentor," "total number of cases," and "academic prestige of program."

This survey provides pediatric ophthalmology fellowship directors a better understanding of the qualities an applicant seeks in their fellowship training. This survey was sent to all physicians of AAPOS including those who were in fellowship over 10 years ago. Different generations value specific qualities differently, such as number of preceptors and fellow call responsibility. Applicants who wish to pursue a more academic career did rank programs qualities with an emphasis on research as more important.

There are a few limitations to this survey. In the survey response, not every question was answered. The response rate was low and we do not know whether respondents differ from the entire cohort that was contact. Our low response rate may be due to fact that the survey was delivered and responded via mail, and in the future an electronic survey might help improve such results. The survey included fellows up to the 2012 academic year. Fellows in more recent years may have similar or different responses. As the millennial generation begins ${ }^{6}$ to enter the fellowship workforce, a repeat survey may be useful. Regardless of these limitations, this survey is the only one to provide useful information for both applicants and fellowship directors.

\section{Authors' Contributions}

All authors contributed to the analysis and interpretation of data, and the drafting and reviewing of the manuscript. All authors gave approval to the version submitted. Dr. Robert Enzenauer is responsible for the overall content as the guarantor and corresponding author.

\section{Funding}

This article was supported in part by a challenge grant from Research to Prevent Blindness to the Department of Ophthalmology.

Conflict of Interest

None.

\section{References}

1 Gedde SJ, Budenz DL, Haft P, Tielsch JM, Lee Y, Quigley HA. Factors influencing career choices among graduating ophthalmology residents. Ophthalmology 2005;112(07):1247-1254

2 Simon JW, Bradfield Y, Smith J, Ahn E, France TD. Recruitment and manpower in pediatric ophthalmology and strabismus. J AAPOS 2007;11(04):336-340

3 Available at: SFMatch.org. Accessed December 5, 2016

4 Shantha JG, Shulman B, Gonzalez M, Hink EM, Durairaj VD. American Society of Ophthalmic Plastic and Reconstructive Surgery fellowship survey: fellows selection criteria for training programs. Ophthal Plast Reconstr Surg 2013;29(06):428-430

5 Beres A, Baird R, Puligandla PS. Success in the Pediatric Surgery Match: a survey of the 2010 applicant pool. J Pediatr Surg 2011;46 (05):957-961

6 Howe N, Strauss W. Millenials Rising: The Next Great Generation. New York: Vintage Books; 2000 